\title{
Chaos and predictability of the Indian summer monsoon
}

\author{
B N GOSWAMI \\ Centre for Atmospheric and Oceanic Sciences, Indian Institute of Science, Bangalore 560012, India
}

\begin{abstract}
Predictability of the Indian summer monsoon is investigated by conducting three multiyear integrations with the Geophysical Fluid Dynamics Laboratory's climate model. The mean monsoon simulated by the model is realistic. It is shown that a significant fraction of the interannual variance of the simulated Indian summer monsoon may be due to internal dynamics. It is discovered that the tropical atmosphere is capable of sustaining a quasi-biennial oscillation (QBO) accounting for most of the internal low frequency variability. It is also shown that neither air-sea interaction nor surface hydrology feedback is essential for the QBO of the model atmosphere. That such a QBO can arise due to modulation of the nonlinear intraseasonal oscillations by the annual cycle is demonstrated using a simple nonlinear dynamical model. The phase and the amplitude of the internal mode is unpredictable and hence may be responsible for limiting the long range predictability of the monsoon.
\end{abstract}

Keywords. Seasonal monsoon; predictability; slowly varying forcing; internal dynamics.

PACS Nos $47.27 ; 92.10 ; 92.20 ; 92.60 ; 95.75$

\section{Introduction}

The weather representing the instantaneous state of the atmosphere and the climate representing the space/time averages are both governed by a set of physical laws. The atmosphere and the coupled ocean-atmosphere system may be represented by a set of equations that include certain approximations in describing some of the physical processes such as radiative heating, convective heating associated with clouds, boundarylayer turbulent fluxes of heat, momentum and mass etc. With initial conditions defined by observations, such a set of equations or a 'model' may be integrated forward in time using a powerful computer. With improved models and improved specification of the initial conditions, what limits our ability to predict the weather? This question was first addressed by Lorenz [1]. Using a simple model, he showed that small errors in the initial conditions would double in about three days. Keeping in mind some of the intrinsic limitations of the observing system, this puts a limit of two to three weeks on our ability to predict the weather. This limit, often known as the 'limit on deterministic predictability', has now been confirmed using more sophisticated models. This limit is governed by the instabilities and nonlinearities of the system. The instabilities make the initial error grow in time while the nonlinearities help the errors to reach a saturation level keeping the system within certain bounds.

In contrast to the tremendous strides made by numerical weather prediction, the climate prediction efforts using deterministic models are still in early stages of 
development. For a while the limit on deterministic predictability acted as a conceptual barrier for deterministic climate prediction as such predictions must be made with a lead time of at least one season. It was thought that no useful prediction beyond the deterministic limit on predictability could be achieved. However, it was demonstrated by Charney and Shukla [2] that although the instantaneous state of the atmosphere (or the weather) may not be predictable beyond 2-3 weeks, the climate or the statistical properties of the atmosphere (such as time and/or space means) may still be predictable beyond this limit. This is possible because the climate is governed by low frequency planetary-scale flow patterns. If these low frequency (LF) planetary-scale flow patterns were solely governed by internal dynamics or instabilities of their own scale or scale interactions with the high-frequency synoptic disturbances, then there will not be much hope for predictions beyond the limit on deterministic predictability. However, these LF planetary-scale patterns are also expected to be governed to a large extent by the forcing associated with slowly varying boundary conditions such as sea surface temperature (SST), soil moisture, snow cover, etc. These slowly varying boundary conditions give rise to slowly varying forcings in the atmosphere that provide significant coherent changes in the planetary scales at LF, leading to potential predictability of the space-time averages. This has been supported by a large number of atmospheric general circulation model (AGCM) studies forced by observed sea surface temperature (SST) variations (see [3] and references therein) and provide the conceptual basis for climate prediction.

Several observational and modeling studies have established that the Indian summer monsoon is linked with several surface boundary forcings. In addition to links with Eurasian snow cover [4-6] and soil moisture over Indian continent [7], the link with Pacific SST and Southern oscillation is considered strong and has been studied by many authors [8-11]. This background led to the optimism that long range dynamical prediction of the Indian summer monsoon one or two seasons in advance may be feasible. As a result, a large number of studies in the last few years have made serious attempts to simulate the interannual variability (IAV) of Indian summer monsoon [12-14] and to hind-cast seasonal mean monsoon rainfall $[15,16]$ using different atmospheric general circulation models (AGCMs). Three important observations made from these studies are summarized below.

First, most models still have a serious problem in simulating the mean summer precipitation over the Indian region. They tend to simulate too little precipitation over the continent. In some cases, even during the summer months a strong inter tropical convergence zone (ITCZ) persists over the equatorial Indian ocean. Second, most models can simulate the interannual variability of some planetary scale component of the monsoon such as the divergent circulation (as given by the velocity potential). However, the simulation of the IAV of the monsoon rainfall differs widely from one model to another [15] indicating great sensitivity of this regional part of the circulation on resolutions and physical parameterizations of the models. In addition, while the prediction of the seasonal mean rainfall in other parts of the tropics (e.g., Sahel or equatorial Pacific) do not seem to be sensitive to small changes in the initial conditions, the simulation of the seasonal mean Indian monsoon rainfall seems to be rather sensitive to small changes in the initial conditions [17]. This indicates that the mean monsoon circulation in the tropics may be unique in that it is not entirely forced by slowly varying boundary forcings but is also governed by internal dynamics to some extent.

Pramana - J. Phys., Vol. 48, No. 2, February 1997 (Part II) 
The limit on predictability of Indian summer monsoon would be determined by the degree to which the mean monsoon is governed by internal dynamics. Quantitative estimates of this contribution to the mean monsoon is currently lacking. In the present study, an attempt is made to make quantitative estimates of contributions from boundary forcings and internal dynamics to the interannual variability of the monsoon. As our primary objective relates to the predictability of the Indian summer monsoon, we select an AGCM whose simulation of mean precipitation during the northern summer over the monsoon region is reasonably close to the observed mean precipitation. Then, the forced variability is estimated from a multi-year integration of the model with observed sea surface temperature as the boundary condition. The internal variability is estimated from a multi-year run of the same model with fixed seasonal cycle SST. Another sensitivity experiment with the fixed seasonal cycle of SST as well as that of the soil moisture has been conducted to derive some insight regarding the origin of the low frequency internal oscillations in the model. The model used and the experiments conducted are described in $\S 2$. The mean monsoon simulation of the model is discussed in $\S 3$. The simulation of the SST forced interannual variations from the observed SST run are discussed in $\S 4$. The interannual variability due to internal dynamics is also examined in this section. The amplitude of interannual variations of Indian summer monsoon indices due to internal dynamics is compared to the amplitude of forced variability. The nature of the low frequency variability in the climatological SST run is also investigated. It is discovered that the model atmosphere exhibits an internal quasi-biennial oscillation. Possible physical mechanisms for the origin of this biennial oscillation are discussed in $\S 5$. A summary of the results is presented in $\S 6$. The implications of our results to the predictability of Indian summer monsoon are also discussed here.

\section{The model and experiments}

The atmospheric model used in this study is a version of the Geophysical Fluid Dynamics Laboratory (GFDL) climate model. It is a spectral model where the dynamic computations are performed using so called spectral element method in which the distribution of a predicted variable is represented by a series of spherical harmonics and grid points. This version has a rhomboidal 30 horizontal resolution ( $30 \mathrm{zonal}$ waves and 30 associated Legendre functions; approximately $3.75^{\circ}$ longitude by $2.25^{\circ}$ latitude resolution) and 14 unevenly spaced sigma levels in the vertical (R30L14 version). The vertical derivatives in the prognostic equations are computed by a centered, second order finite difference scheme. The lower resolution version (R15L09) described by Gordon and Stern [18] has been used in many climate studies $[19,20]$. The physical processes and their parameterizations included in this version of the model are briefly described below.

The distribution of insolation at the top of the model atmosphere is prescribed. It varies seasonally but does not have a diurnal cycle. The solar constant is $1365 \mathrm{~W} / \mathrm{m}^{2}$ and the mixing ratio of carbon dioxide is taken as $345 \mathrm{ppm}$. Solar radiation is computed using method similar to that used by Lacis and Hansen [21] except that the bulk optical properties of clouds such as reflectivity and absorptivity are prescribed. It includes multiple reflections by clouds but does not account for aerosols. Terrestrial long wave radiation is computed following the method described by Rodgers and Walshaw [22] and

Pramana - J. Phys., Vol. 48, No. 2, February 1997 (Part II) 


\section{B N Goswami}

as modified by Stone and Manabe [23]. It includes the effect of the water vapour continuum. Ozone is prescribed as a function of latitude, height and season based on data from Hering and Borden [24].

Precipitation is computed following the 'moist convective adjustment scheme' described by Manabe et al [25]. Soil moisture is computed by the so called bucket method [26]. Over the continents surface temperature is computed from the condition of heat balance at the surface assuming a zero heat capacity. The model also include a gravity wave drag formulation developed by Hayashi and described by Broccoli and Manabe [27]. A simple mixing length theory for vertical diffusion of momentum, heat and moisture is also included. Prediction of cloud cover is done following the scheme used by Wetherald and Manabe [28].

Three multi-year integrations are carried out with the model. The three experiments are briefly described below.

OBS-SST run: In this run the observed monthly mean global SST [29] is prescribed. Monthly mean values are interpolated from one month to another to produce the required daily values. The soil moisture and snow cover are predicted. The model was integrated for 15 years with observed SST from January 1979 through December 1993 as boundary conditions. The model was initially spun up with mean seasonal cycle SST for five years from a resting isothermal state. The low frequency interannual variations of the observed SST associated with the El Nino and southern oscillation (ENSO) force low frequency interannual variations in the atmosphere in this run.

CLI-SST run: In this run mean seasonal cycle global SST was prescribed which was repeated every year. The soil moisture and snow cover are predicted. The mean seasonal cycle of SST was taken from Levitus [30]. The climatological sea-ice used in this run was taken from Walsh and Johnson [31] and Zwally et al [32]. The initial conditions for this run consisted of a resting isothermal atmosphere. The model was integrated for 40 years and the last 20 years are considered here. The model atmosphere was found to reach a quasi-equilibrium after about 15 years initial integration. In this run, except for the annual cycle forcing, there is no external interannual forcing. Internal dynamics and feedback with surface hydrological processes could still give rise to some interannual variability.

CSST-SM run: Both the seasonal cycle of SST and the seasonal cycle of soil moisture are prescribed in this run. The mean seasonal cycle of SST used was same as in the CLISST run. The seasonal cycle of soil moisture at each grid point were constructed from the 15 year simulations of the OBS-SST run. The snow cover feedback is also eliminated from the model. This integration was carried out for 18 years. In this run, even the surface hydrological feedback is eliminated. Therefore, any interannual variability in this run must arise purely due to internal dynamics in the presence of the annual cycle forcing. Monthly mean output is analyzed from all the runs.

\section{Mean monsoon simulated by the model}

The Asian summer monsoon has some unique characteristic features such as the low level westerly jet over the north Arabian sea and the easterly jet in the upper troposphere. The maximum strength of the easterly jet is at around $150 \mathrm{mb}$ with its center shifted to the east

$$
\text { Pramana - J. Phys., Vol. 48, No. 2, February } 1997 \text { (Part II) }
$$


OBSERVED PREC.

JAN

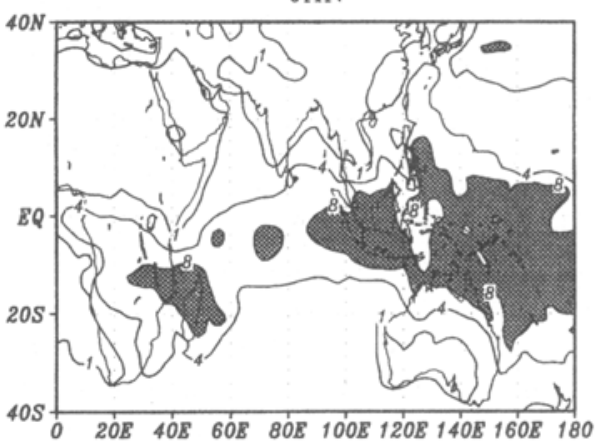

AUG

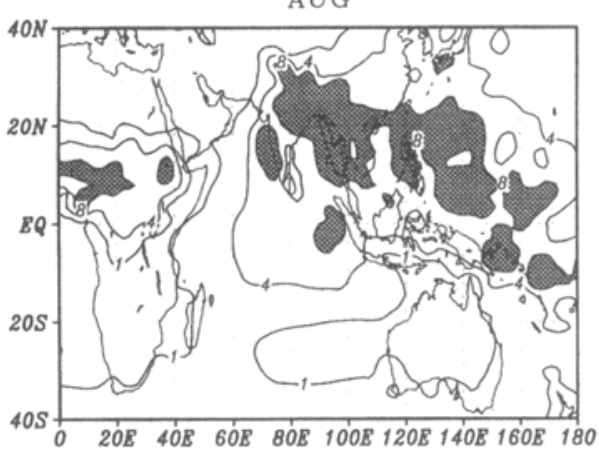

JJAS

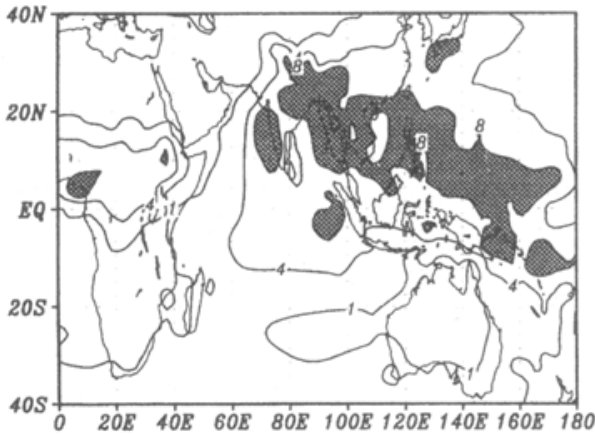

MODEL PREC.
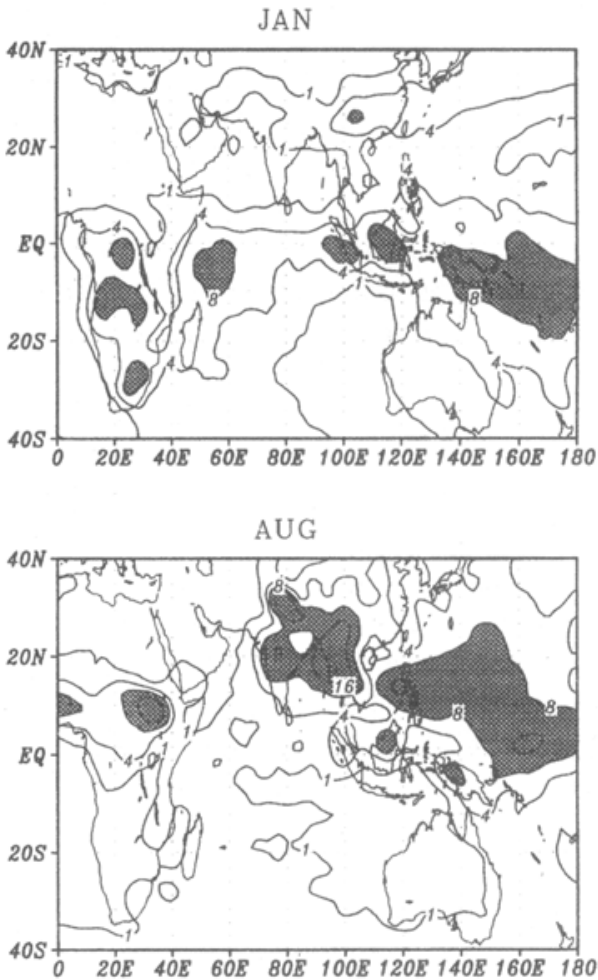

JJAS

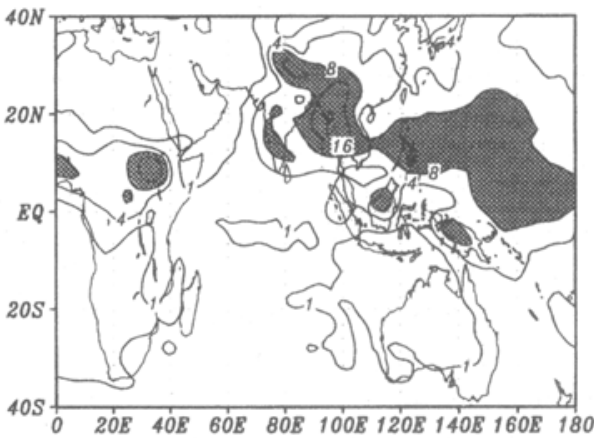

Figure 1. Mean January (JAN), August (AUG) and June-September (JJAS) precipitation. The mean derived from the OBS-SST run (right panel) is compared with observations ([33], left panels). Contours are 1,4,8,16,32 mm/day. Precipitation greater than $8 \mathrm{~mm} /$ day is shaded.

of the low level westerly jet center by about $10^{\circ}$ longitude. In addition, the movement of the mean position of the ITCZ to the Indian continent and relatively sudden 'onset' and 'retreat' of the monsoon constitute other characteristic features of the Indian 


\section{B N Goswami}

summer monsoon. In this section, we examine the GFDL R30L14 model's ability to simulate these features. As described in the previous section, we have three different multi-year simulations with the same model. Since the annual cycle of the SST is nearly identical and the annual cycle of the solar forcing is identical in all three experiments, the mean annual cycle derived from the three runs should also be nearly identical. It is indeed found to be so (not shown). In figure 1, we show the precipitation climatology for January, August and June-September mean from the OBS-SST run and compare them with observations [33]. During winter (January), the position of the ITCZ is correctly simulated. However, the model simulates a smaller area of heavy precipitation $(>8 \mathrm{~mm} /$ day) over Indonesia than observed. During summer (August), the ITCZ does move to a position over the Indian continent. The maximum over the northern Bay of Bengal is well simulated. The precipitation over most of Indian continent is reasonably well simulated. The maximum off the western coast is not well simulated. This is related to the model's resolution being insufficient to resolve the Western Ghat mountains adequately. The seasonal mean (June-September) precipitation is also shown here as in our discussion of interannual variability we shall be referring to seasonal mean anomalies. It is noted that the seasonal mean precipitation is also well simulated by the model. The simulated precipitation over central India is slightly weaker than observed. Considering the low resolution of the model and the rather simple parameterization of cumulus convection employed by the model, the simulation of the mean precipitation is realistic. The model, however, underestimates the weaker second precipitation zone over the equatorial Indian ocean during northern summer.

We have also examined the simulation of the Somali jet, the easterly jet in the upper troposphere and the onset and retreat of monsoon by the model. It is found the model does a reasonably good job of simulating all these features.

\section{Interannual variability: SST forced versus internal}

In this section we discuss the interannual variability of some monsoon indices simulated by the model in the OBS-SST run. Figure 2 shows the interannual variability of the JuneSeptember (JJAS) normalized precipitation anomalies. The top panel contains the observed all India rainfall anomalies. 1982 and 1987 were deficient rainfall years while 1983 and 1988 were excess rainfall years. The lower panel shows simulated precipitation averaged only over 'Indian region' $\left(70^{\circ}-95^{\circ} \mathrm{E}, 10^{\circ}-30^{\circ} \mathrm{N}\right.$, including the oceanic region included in this box). The model captures the variability during 1987 and 1988 but fails to do so during 1982. In general the model's skill in simulating the observed interannual variability of the Indian summer monsoon is rather modest. Out of the 15 years the sign of the interannual anomaly is correctly simulated in 9 years.

In order to estimate how much of the interannual variability of the monsoon discussed above is due to SST forcing and how much may be due to internal dynamics, we compare the interannual variability among the OBS-SST and CLI-SST runs. Figure 3 shows the precipitation averaged over the 'monsoon region' and the 'broad scale monsoon shear index'. The 'broad scale monsoon shear index' is defined as the zonal wind shear (U at $170 \mathrm{mb}-\mathrm{U}$ at $860 \mathrm{mb}$ ) averaged over EQ-20 $\mathrm{N}$ and $40^{\circ}-100^{\circ} \mathrm{E}$ [11]. Both indices are

Pramana - J. Phys., Vol. 48, No. 2, February 1997 (Part II) 

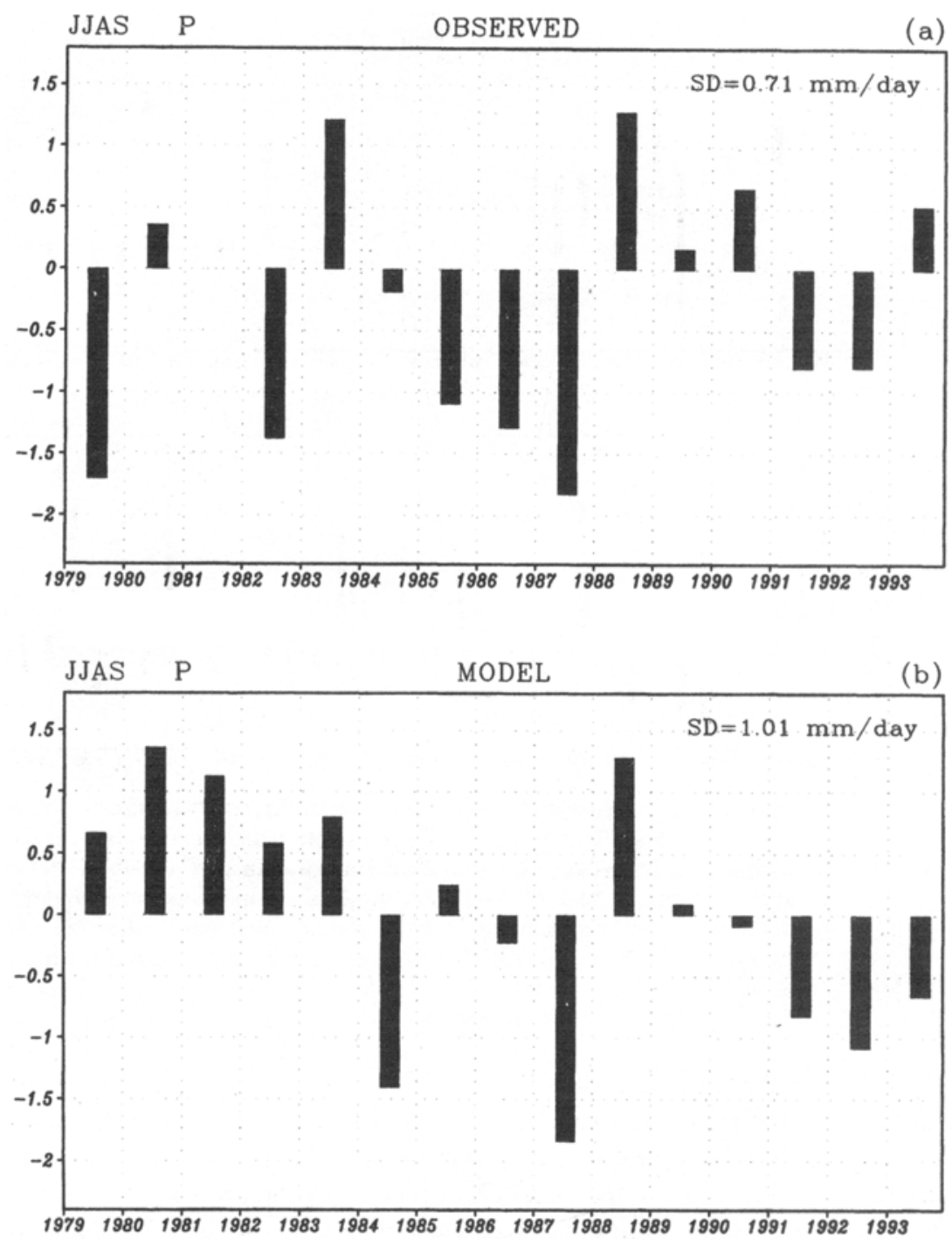

Figure 2. Comparison of simulated interannual variability of the seasonal mean monsoon (June-September) precipitation with observations. (a) Observed 'All-India' precipitation anomalies, (b) the simulated precipitation anomalies averaged over India and the Bay of Bengal $\left(70^{\circ}-95^{\circ} \mathrm{E} 10^{\circ}-30^{\circ} \mathrm{N}\right)$. In both cases the precipitation anomalies are normalized with their own standard deviation.

averaged over the summer monsoon season, June-September. An examination of the interannual variability of the precipitation index shows that, although the observed SST tends to enhance the variability, the internal dynamics alone produces considerable interannual variability. The largest precipitation anomalies in the OBS-SST run occur either during strong warm or cold events in the Pacific $(1987,1988)$. The amplitude of the interannual variability in the remaining 'normal' years is quite close to the interannual

\section{Pramana - J. Phys., Vol. 48, No. 2, February 1997 (Part II)}




\section{B N Goswami}
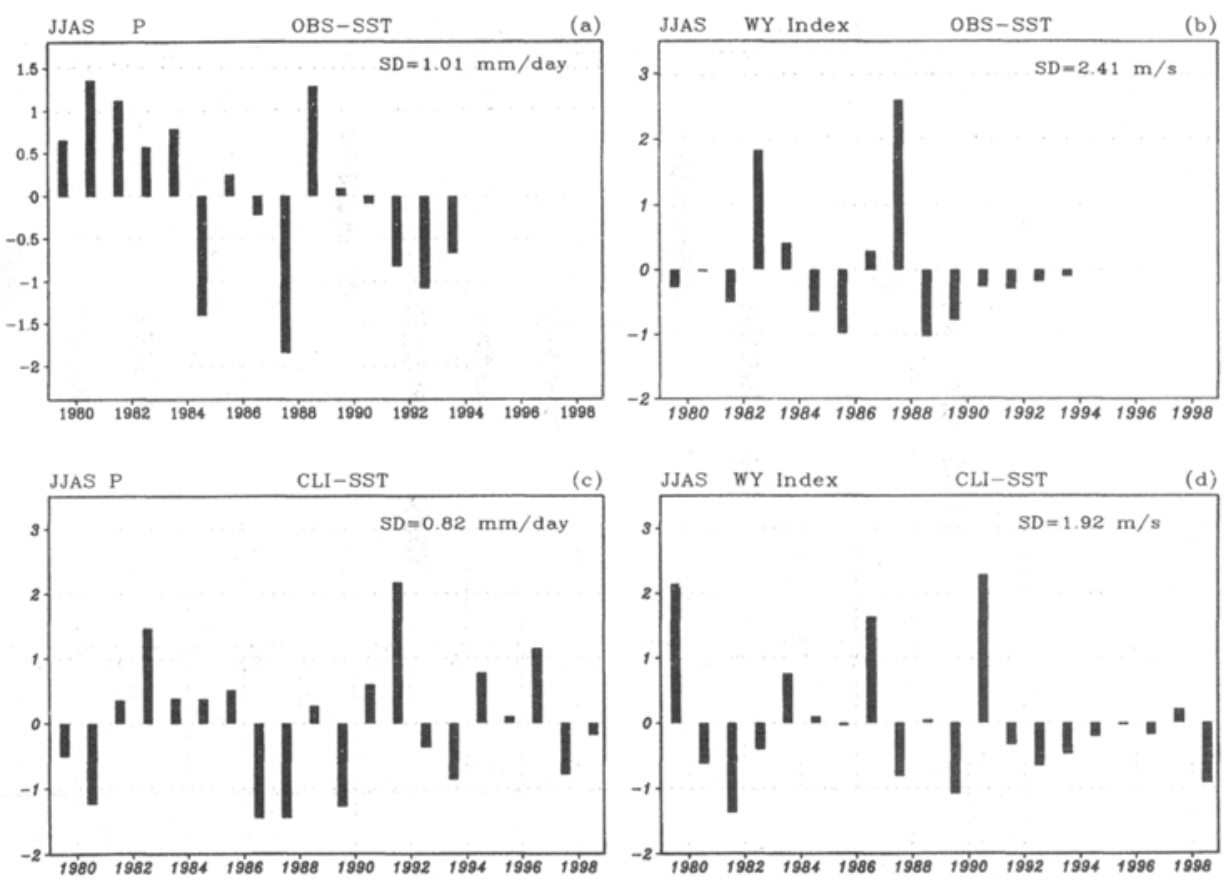

Figure 3. Comparison of interannual variability of two summer monsoon indices between OBS-SST and CLI-SST runs. Left panels correspond to JJAS averaged precipitation (mm/day) averaged over Bay of Bengal $\left(70^{\circ}-95^{\circ} \mathrm{E}, 10^{\circ}-30^{\circ} \mathrm{N}\right)$, right panels correspond to JJAS averaged 'broad scale monsoon shear index' in $\mathrm{m} / \mathrm{s}$. The interannual standard deviations are noted in each panel. Results of 20 years of simulation are shown for the CLI-SST runs. The year labeling for the CLI-SST run are arbitrary and has been made to match with that of the OBS-SST run for the first 15 years. The last five years of the plot for OBS-SST run is left blank.

variability in the CLI-SST run. This indicates that strong cold (warm) events in the Pacific are associated with increased (decreased) precipitation over the monsoon region. However, if the SST anomalies are not very large during the summer season, the internal variability could dominate the variability of the monsoon precipitation. This is consistent with the predictability studies of Brankovic and Palmer [34]. The simulation of the "broad scale monsoon shear index' also shows that the amplitude of the interannual variability generated purely by internal dynamics (CLI-SST) is, comparable to that forced by the slowly varying SST boundary forcing (OBS-SST). In the OBS-SST run the entire variability is dominated by the 1987 event. The interannual variability produced by the internal dynamics is often larger than that in the SST boundary forced run.

\subsection{A Quasi-biennial internal oscillation}

From the above discussions, it is clear that the model atmosphere can generate significant interannual variability even in the absence of any external forcing with interannual periods. What then is responsible for these interannual variations? Are there significant natural oscillations of the system or are they simply part of a red-noise process? To get

Pramana - J. Phys., Vol. 48, No. 2, February 1997 (Part II) 

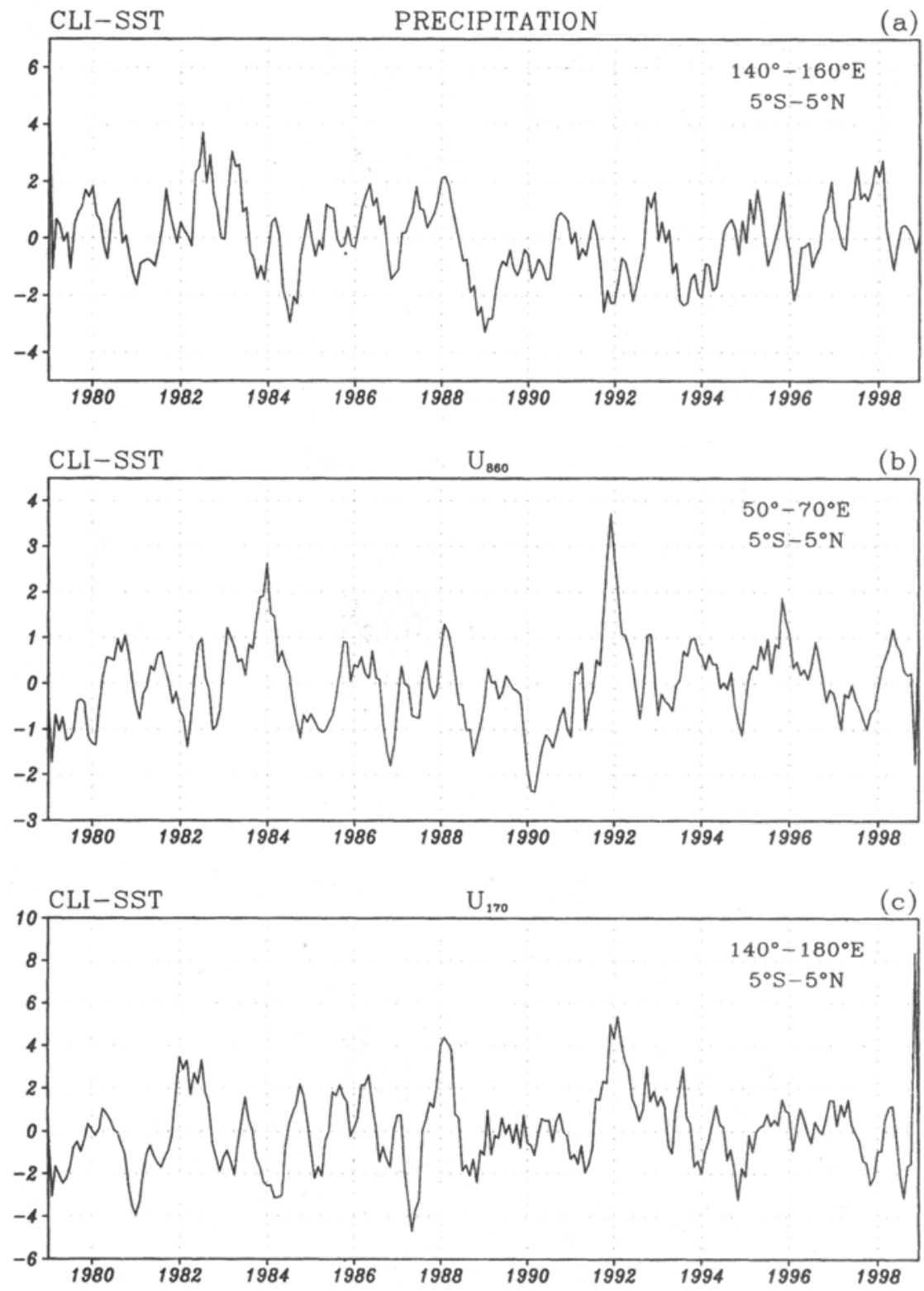

Figure 4. The interannual variability in the CLI-SST simulation. Time series of 5 month running mean equatorial $\left(5^{\circ} \mathrm{S}-5^{\circ} \mathrm{N}\right)$ precipitation $P\left(\mathrm{~mm} /\right.$ day, $\left.140^{\circ}-160^{\circ} \mathrm{E}\right)$ and zonal wind at $170 \mathrm{mb}\left(140^{\circ}-180^{\circ} \mathrm{E}\right)$ and $860 \mathrm{mb}\left(50^{\circ}-70^{\circ} \mathrm{E}\right)(\mathrm{m} / \mathrm{s})$.

some idea regarding the temporal variability of the low frequency internal oscillations, we show 5 month running means of three different variables averaged over three different regions from the CLI-SST run in figure 4. The precipitation is averaged over $5^{\circ} \mathrm{S}-5^{\circ} \mathrm{N}$ and $140^{\circ}-160^{\circ} \mathrm{E}$. The zonal winds at $170 \mathrm{mb}$ and $860 \mathrm{mb}$ are averaged over $5^{\circ} \mathrm{S}-5^{\circ} \mathrm{N}$ 


\section{B N Goswami}
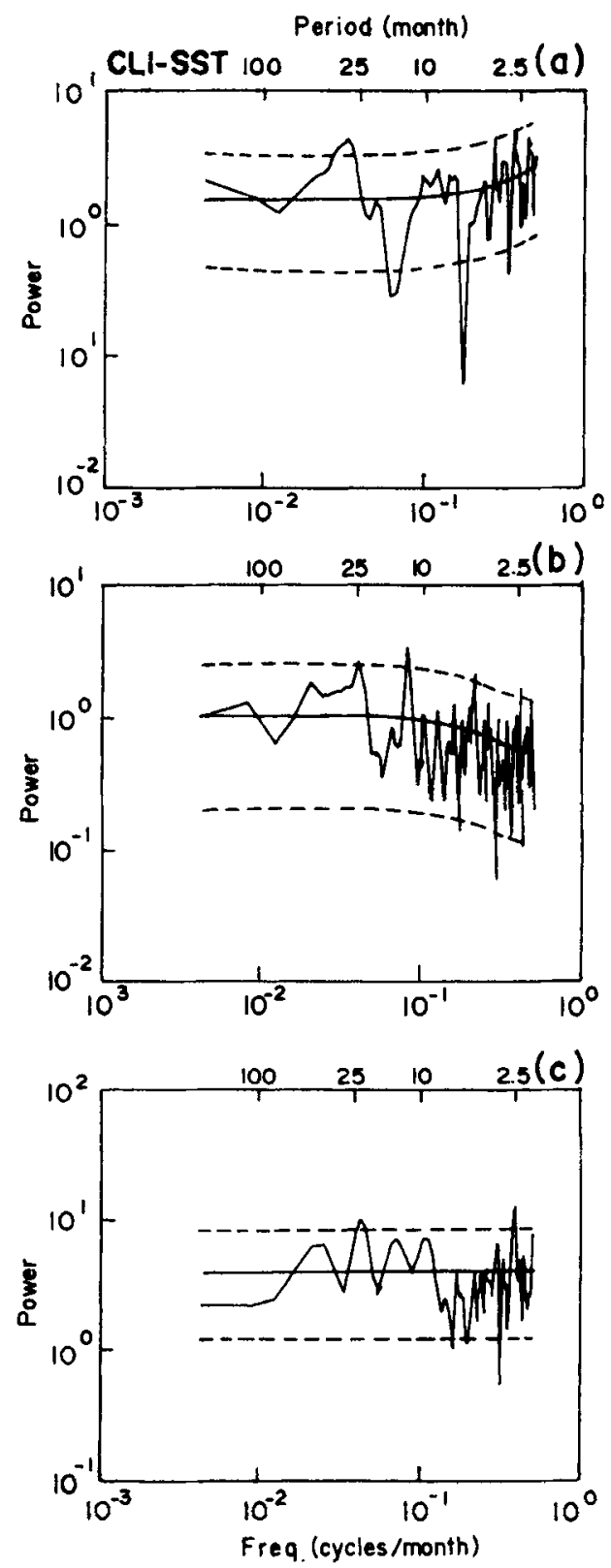

Figure 5. Power spectra of un-filtered monthly mean precipitation and zonal winds averaged over same regions shown in figure 4, for the CLI-SST run. (a) Precipitation $\left(5^{\circ} \mathrm{S}-5^{\circ} \mathrm{N}, 140^{\circ}-160^{\circ} \mathrm{E}\right)$, (b) zonal wind at $860 \mathrm{mb},\left(5^{\circ} \mathrm{S}-5^{\circ} \mathrm{N}, 50^{\circ}-70^{\circ} \mathrm{E}\right)$, (c) zonal wind at $170 \mathrm{mb}\left(5^{\circ} \mathrm{S}-5^{\circ} \mathrm{N}, 140^{\circ}-180^{\circ} \mathrm{E}\right)$. The theoretical red noise spectrum based on lag 1 auto-correlation (thick solid) and the $95 \%$ confidence limits are also shown.

and $140^{\circ}-180^{\circ}$ and $50^{\circ}-70^{\circ} \mathrm{E}$ respectively. It is clear that all the three variables show significant low frequency variability. In particular the precipitation time series tends to indicate a quasi-biennial variability. Quasi-biennial variations can be also be detected in 
the wind time series. This preliminary examination indicates that the model atmosphere has a quasi-biennial internal oscillation. A spectrum analysis of the original monthly mean time series confirms this (figure 5). The $95 \%$ confidence limits in figure 5 are calculated from the lag 1 auto correlations of the original time series. It is noteworthy that all three time series have a statistically significant peak around a biennial periodicity. We must add here that the three regions shown here have been selected after some trial and error. This is because the biennial variability has regional scale spatial structure. Therefore, if we average the anomalies over some arbitrary regions, there is a danger of canceling positive and negative anomalies leading to an insignificant signal.

\section{Possible mechanisms}

Air-sea coupling, air-land surface coupling [35-37] and interaction between nonlinear intra-seasonal oscillations and the annual cycle [38] have been invoked to explain the origin of the observed biennial component of the interannual variability in the Indian and Pacific region. As climatological SST is prescribed in our run, ocean-atmosphere coupling could not be responsible for our biennial oscillation. The other possibility is the atmosphere and land-surface feedback as envisaged by Meehl [37]. Qualitatively, this feedback may be described as follows. The strength of the monsoon circulation is related to the north-south temperature gradient over the region. A strong monsoon is associated with a strong north-south temperature gradient and results in excess precipitation and soil moisture over land. If the enhanced soil moisture persists through the next three seasons, land would be wetter than normal prior to the next monsoon. Evaporation and enhanced latent heat flux would result in cooler land temperature and weaker north-south temperature gradient leading to a weaker monsoon. A weak monsoon this year would be associated with below normal precipitation which through the same arguments would lead to a strong north-south temperature gradient and a strong monsoon next year. In this manner the cycle could be repeated every two years. While this mechanism could work in principle, there is no convincing evidence that soil moisture anomalies persist for three or more seasons. In order to determine whether this feedback is at work in producing the biennial oscillation in our model atmosphere, we carried out an additional multi-year run in which in addition to the annual cycle of SST, the annual cycle of the soil moisture and snow cover were also prescribed (CSST-SM). This experiment was conducted for 18 years. We then carried out time series and spectrum analysis of various monthly mean fields as before. It is found that this run also contains a significant biennial signal as a dominant part of its interannual variability. The spectra of un-filtered monthly mean precipitation averaged over two locations are shown in figure 6 . It is clear that both the time series show a rather strong and significant peak with a period around two years. Therefore, it appears that the biennial oscillation of our model atmosphere does not owe its origin to a ground hydrology feedback as envisaged by Meehl [37].

This leaves the possibility of producing a biennial signal through interaction between atmospheric high frequency transients (synoptic and intraseasonal oscillations) and the annual cycle as a candidate for the biennial oscillation in our model atmosphere. Lorenz [39] first addressed whether the nonlinear weather events (synoptic systems) in the middle latitude modulated by the annual cycle forcing could give rise to any significant 

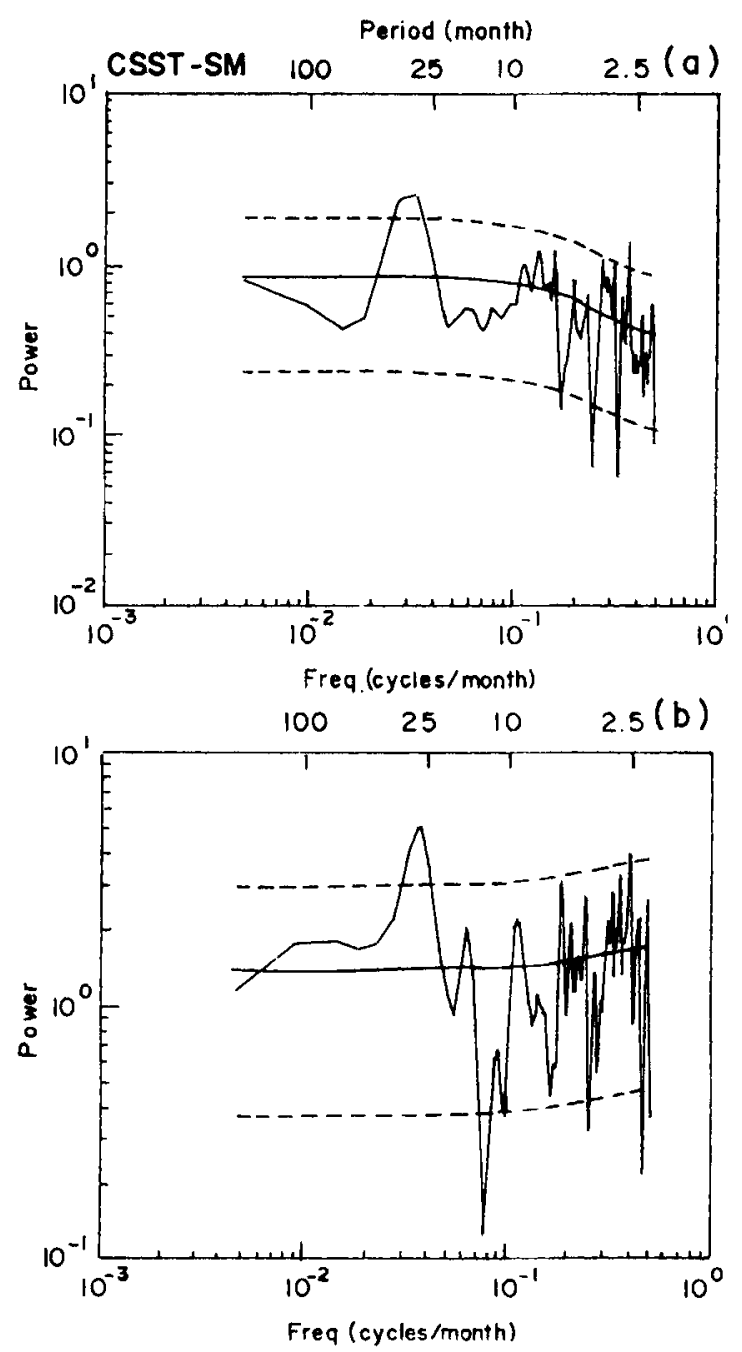

Figure 6. Power spectra of precipitation averaged between $5^{\circ} \mathrm{S}-5^{\circ} \mathrm{N}$ and over two longitudinal belts (a) $\left(70^{\circ}-95^{\circ} \mathrm{E}\right)$, and (b) $\left(120^{\circ}-140^{\circ} \mathrm{E}\right)$ from CSST-SM simulation. Other conventions are same as in figure 5.

interannual variability. He showed that due to the intransitive nature of the nonlinear high frequency component, a periodic forcing can give rise to some interannual variability. However, there was no suggestion of a preferential selection of the biennial oscillation. In contrast to the mid latitude, in the tropics the day to day weather fluctuations are less energetic but the intraseasonal oscillations such as the active break phases of the monsoon are quite energetic. Here we show that the modulation of the nonlinear atmospheric 'intraseasonal oscillations' by the annual cycle could result in an atmospheric biennial mode. To demonstrate this, we choose the following prototype nonlinear system [39]

$$
\dot{X}=-Y^{2}-Z^{2}-a X+a F,
$$

Pramana - J. Phys., Vol. 48, No. 2, February 1997 (Part II) 

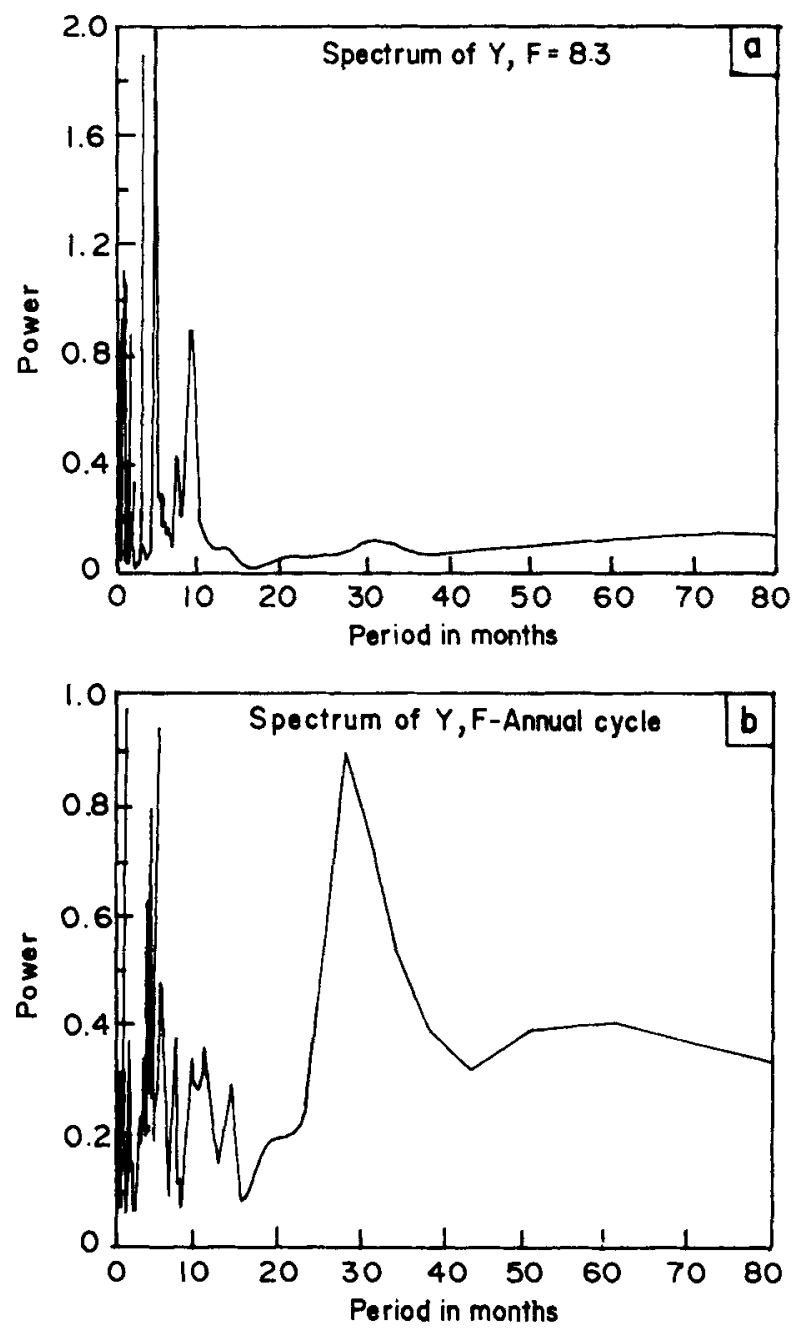

Figure 7. Spectrum of daily $Y$ with $c=0.5$. (a) for a constant $F=8.3$ and (b) annual cycle of $F=7.0+2.0 \cos \pi t / 1$ year.

$$
\begin{aligned}
& \dot{Y}=X Y-b X Z-c Y+G \\
& \dot{Z}=b X Y+X Z-c Z
\end{aligned}
$$

where $X$ may be considered as the zonally symmetric component while $Y$ and $Z$ may be interpreted as non-zonal components. $F$ is the zonally symmetric forcing (e.g., solar forcing) while $G$ is the non-zonal forcing arising out of land-ocean contrasts. Values of the parameters $a$ and $b$ representing dissipation and strength of eddy-mean flow interaction used by Lorenz are retained ( $a=0.25$ and $b=4.0$ ). Also, $G=1.0$. Original equations of Lorenz and the parameters are all scaled by a factor $c$. For $c=1.0$, the spectrum of the nonlinear system within the chaotic regime shows maximum power around synoptic frequencies (around one week). With $c=0.5$, however, the preferential period in the chaotic regime shifts to intraseasonal range ( 3 to 5 months). In figure 7 (a), 


\section{B N Goswami}
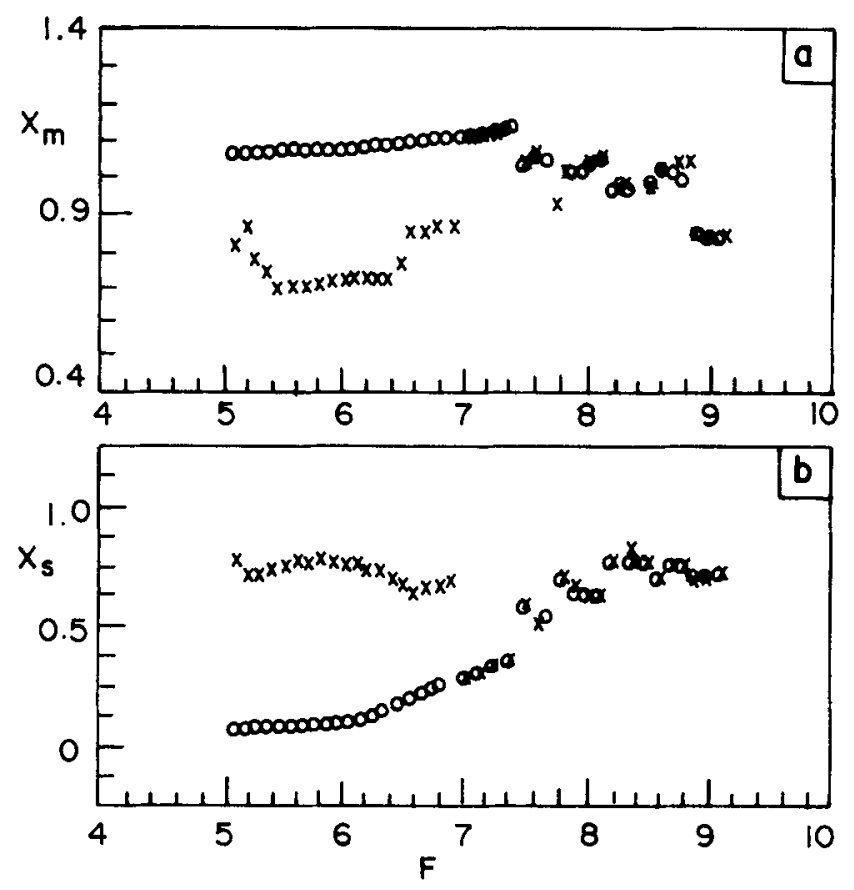

Figure 8. Some gross features of the attractors for different values of constant forcing, $F$. (a) Long term mean, $X_{m}$ and (b) standard deviation, $X_{s}$. The two symbols represent values obtained with two different initial conditions for each forcing.

the spectrum of daily $Y$ for a fixed $F=8.3$ is shown based on the last 100 years of a 150 year integration. Next we introduced an annual cycle forcing with $F=7.0+2.0 \cos \pi t / \tau$, where $\tau$ is one year. Again, the spectrum of daily $Y$ is shown based on the last 100 yeas of a 150 year integration. The modulation of the intraseasonal oscillations by the annual cycle clearly gives rise to a significant biennial oscillation (figure $7 \mathrm{~b}$ ). If, however, $c=1.0$ and the nonlinear oscillations are primarily confined to the synoptic range, the preferential excitation of the biennial mode is very weak (not shown).

How does periodic variation of forcing for the atmosphere with a period of 1 year generate responses at all low frequencies? This was discussed by Lorenz [39] in detail. To understand how the slowly varying forcing introduces the low-frequency response, we need to examine the nature of variations of the nonlinear system (1)-(3) for different values of the steady forcing. In figure 8 , we show some gross characteristics of the attractors (long-term mean and standard deviation) of the system (1)-(3) for a range of values of $F$. The two symbols represent attractors attained from two different initial conditions. The system has periodic attractors for $F$ between 5.0 and 7.5. For $F$ between 7.5 and 8.8 , the system has a chaotic attractor. Beyond $F=8.8$, again the system goes to a periodic regime. We note that for $F$ between 5.0 and 7.0 , the system has at least two periodic orbits, one with high amplitude and low mean, while the other with low amplitude and higher mean. Within the chaotic regime too, the system tends to have two preferred regimes, one with large amplitude oscillations with low mean (active regime) and another with small amplitude oscillations with high mean (weak regime). This is seen in figure 9 where the frequency distribution of mean and standard deviation calculated

Pramana - J. Phys., Vol. 48, No. 2, February 1997 (Part II) 

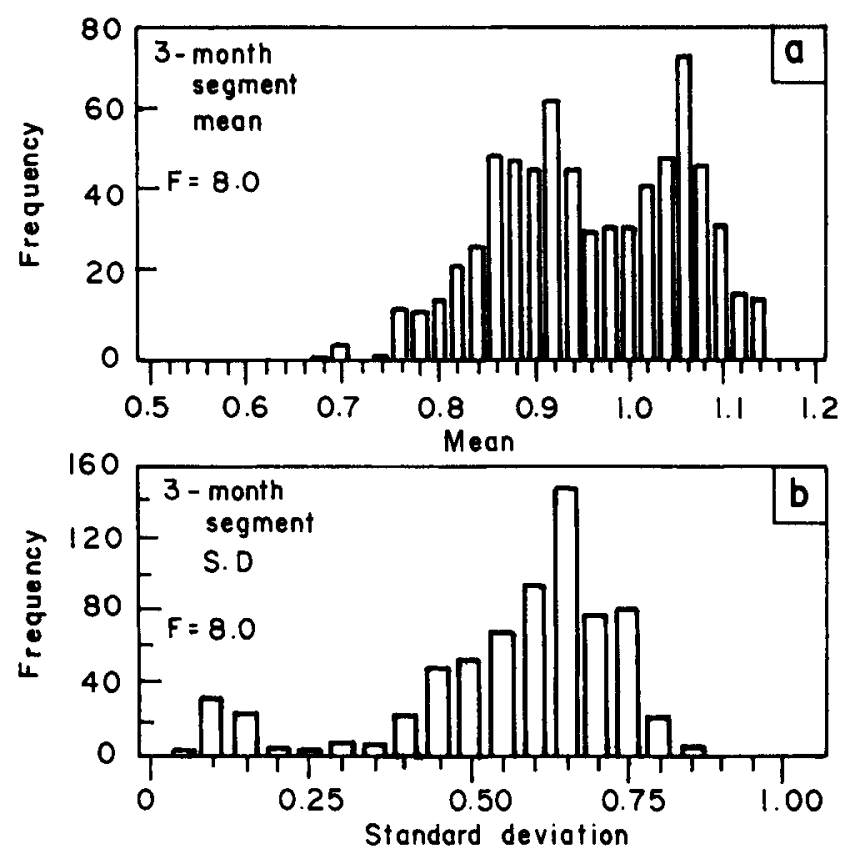

Figure 9. Frequency distribution of (a) mean and (b) standard deviation of three month segments for $F=8.0$ over a period of 184 years.

over three month segments over a period of 184 year with a constant $F=8.0$ (chaotic regime) is shown. Both the standard deviation and the short term mean show the tendency for two preferred regimes.

With this background, we may try to understand the response of the nonlinear system when the forcing changes periodically. When the forcing varies annually between two extremes, say between $F=9$ and $F=5$, the system reaches a chaotic attractor that consists of a strong and a weak regime. The two regimes resemble the orbits of the multiple periodic attractors of constant forcings discussed earlier. Whether the system would tend to visit the weak or the strong regime in a given period of the forcing depends on the previous history of state (or initial conditions, in a loose manner). At many of these values of $F$, when they are held constant, the system may possess multiple periodic attractors that depend on the initial conditions. But when the forcing is varying because of chaos, the system reaches a different state on the same day (or same value of $t$ ) of every year. This difference determines the difference in the subsequent behaviour of the systemwhether to visit the strong or the weak regime. This essentially is why the annual cycle itself is capable of introducing some interannual variability. It appears that in one year the system tends to reside more in the low amplitude-high mean state while in another year it tends to reside in the high amplitude low mean state giving rise to a biennial variability.

\section{Summary of results and implications for monsoon predictability}

The interannual variability of the Indian summer monsoon simulated by three multi-year simulations with the GFDL R30L14 model is studied. The monsoon climatology of 


\section{B N Goswami}

the model is realistic including the position and strength of the low level westerly jet, upper level easterly jet and precipitation over continental India. The skill of simulation of interannual variability of the Indian summer precipitation by the GFDL climate model is only modest. Most general circulation models are found to be deficient in simulating the observed interannual variability of the Indian summer monsoon precipitation [15]. The rather poor predictability of Indian summer monsoon precipitation is shown to be due to the fact that the interannual variability forced by slowly varying SST over the Indian region is comparable or even weaker than that due to internal dynamics.

Further examination of the nature of the interannual variability in the CLI-SST run reveals that much of the interannual variability of the model is due to a significant biennial oscillation of the model atmosphere. The CSST-SM experiment was carried out to address whether the biennial oscillation could have resulted from a soil moistureatmosphere feedback or whether it was internal to the atmosphere. The fact that a significant biennial oscillation is seen even in the fixed soil moisture run rules out the possibility that ground hydrology feedback is responsible for the biennial oscillation. This leaves the possibility of producing a biennial signal through interaction between atmospheric high frequency transients (synoptic and intra-seasonal oscillations) and the annual cycle as proposed by Goswami [38], as a candidate for the biennial oscillation in our model atmosphere. This was demonstrated with a simple paradigm model of the tropical atmosphere. The annual cycle may be considered as a slowly varying forcing for the nonlinear atmospheric high frequency oscillations. As the nonlinear atmospheric oscillations go through a chaotic regime during parts of the slowly varying periodic forcing, it can result in a low frequency tail in the atmospheric oscillations.

The biennial internal oscillation is likely to be a major limiting factor for prediction of seasonal monsoon precipitation. The biennial mode has largest amplitude around the precipitation zone over the Indonesian region. As the SST forced response is relatively weak over the Indian region, and the biennial internal mode has large amplitude, it may dominate the interannual variability. Although the amplitude of the biennial mode is large over northern Australia, the SST forced response is also large. As a result the biennial mode cannot dominate the interannual variability over northern Australia. Over the Sahel region in Africa the amplitude of the biennial oscillation is very weak. Therefore, the interannual variations over Sahel are again primarily governed by SST variations. These conclusions from our analysis are consistent with conclusions that the seasonal predictions of precipitation over the Sahel [17] and northern Australia based on SST can be made with much greater confidence than can be done over the Indian monsoon region [34]. The discovery of a quasi biennial internal oscillation of the tropical atmosphere limiting the predictability of the Indian monsoon needs to be reexamined with other general circulation models.

\section{Acknowledgments}

The author is indebted to Suki Manabe without whose time, help and encouragement this work could not have been completed. He made the results of the already existing CLISST experiment with the same model available and helped in extending the OBS-SST run

$$
\text { Pramana - J. Phys., Vol. 48, No. 2, February } 1997 \text { (Part II) }
$$


for the latest five years. He also got the new CSST-SM run conducted for this study. A number of insightful discussions with him helped the author design the experiments. This work is partially supported by a grant from Department of Science and Technology, Government of India. Some of the calculations were carried out at the Supercomputer Education and Research Centre of the Indian Institute of Science.

\section{References}

[1] E N Lorenz, Tellus 17, 321 (1965)

[2] J G Charney and J Shukla, Predictability of monsoons, Monsoon Dynamics edited by $J$ Lighthill and R P Pearce (Cambridge University Press, Cambridge, 1981) vol. 99

[3] B N Goswami, V Krishnamurthy and N H Saji, Mon. Weather Rev. 123, 1677 (1995)

[4] D J Hahn and J Shukla, J. Atmos. Sci. 33, 2461 (1976)

[5] R R Dickson, J. Climate Appl. Meter. 23, 171 (1984)

[6] A D Vernekar, J Zhou and J Shukla, J. Climate 8, 248 (1995)

[7] J Shukla and Y Mintz, Science 214, 1498 (1982)

[8] G T Walker, Mem. Indian Meteor. Dept. 23, 23 (1924)

[9] J Shukla and D A Paolino, Mon. Weather Rev. 111, 1830 (1983)

[10] T Yasunari, Bull. Am. Meteor. Soc. 72, 1331 (1991)

[11] P J Webster and S Yang, Quart. J. Roy. Meteor. Soc. 118, 877 (1992)

[12] T N Palmer, C Brankovic, P Viterbo and M J Miller, J. Climate 5, 399 (1992)

[13] F W Zwiers, J. Climate 6, 470 (1993)

[14] T C Chen and M C Yen, J. Climate 8, 1403 (1994)

[15] K Sperber and T N Palmer, Atmospheric Model Inter-comparison Project: Monsoon Simulations, Proc. Int. Conf. on Monsoon Variability and Prediction, Trieste, May 9-13, 1994, WMO/TD-619, 601

[16] M Fennessy and J Shukla, Simulation and predictability of monsoons, Proc. Int. Conf. on Monsoon Variability and Prediction, Trieste, May 9-13, 1994 WMO/TD-619, 567

[17] T N Palmer and D Anderson, Quart. J. Roy. Meteor. Soc. 120, 755 (1994)

[18] C T Gordon and W Stern, Mon. Weather Rev. 110, 625 (1982)

[19] N C Lau and M Nath, J. Climate 7, 1184 (1994)

[20] S Manabe and R J Stouffer, J. Climate 7, 5 (1994)

[21] A Lacis and J Hensen, J. Atmos. Sci. 31, 118 (1974)

[22] C D Rodgers and C D Walshaw, Quart. J. Roy. Meteor. Soc. 92, 67 (1966)

[23] H M Stone and S Manabe, Mon. Weather Rev. 96, 735 (1968)

[24] W S Hering and T R Borden Jr., Mean measurements of ozone density over north America, 1963-1964. Environmental Research Papers, Report 162 (US Air Force Res. Lab., Mass., 1965)

[25] S Manabe, J Smagorinsky and R F Strickler, Mon. Weather Rev. 93, 769 (1965)

[26] S Manabe, Mon. Weatehr Rev., 97, 739 (1969)

[27] A J Broccoli and S Manabe, J. Climate 5, 1181 (1992)

[28] R W Wetherald and S Manabe, J. Atmos. Sci. 45, 1397 (1988)

[29] R Reynolds, J. Climate 1, 75 (1988)

[30] C Levitus, Climatological atlas of the world ocean. NOAA Professional Paper No. 13 (U.S. Department of Commerce, Rockville, MD, 1982)

[31] J E Walsh and C M Johnson, J. Phys. Oceanogr. 9, 580 (1979)

[32] H M Zwally, J C Comiso, C L Parkinson, W J Campbell, F D Carsey and P Gloersen, Antarctic sea ice 1973-1976: satellite passive microwave observations. NASA SP-459, (NTIS N84-10718/4), (1983)

[33] D Legates and C J Willmott, Int. J. Climatol. 10, 111 (1990)

[34] C Brankovic and T Palmer, Predictability of summer monsoon, Proc. Int. Conf. on Monsoon variability and prediction, Trieste, May 9-13, 1994, WMO/TD-619, 629

[35] G A Meehl, Mon. Weather Rev., 115, 27 (1987)

$$
\text { Pramana - J. Phys., Vol. 48, No. 2, February } 1997 \text { (Part II) }
$$




\section{B N Goswami}

[36] G A Meehl, J. Climate 6, 31 (1993)

[37] G A Meehl, J. Climate 7, 1033 (1994)

[38] B N Goswami, J. Climate 8, 524 (1995)

[39] E N Lorenz, Tellus 42A, 378 (1990) 